\title{
What future for UK general practice? Enlarge, adapt, or perish?
}

It is almost forever lost: the traditional family doctor - well known in the neighbourhood, caring for individuals from birth to the grave, always available for his patients (and friends). The fundamental gatekeeping element of general practice is under attack - can't nurses do it? With the proliferation of salaried doctors the self-employed status of GPs is being eroded. Revalidation - relicensure, recertification, and remediation - is coming to stay, but with it the massive logistical challenge of how to regulate tens of thousands of independent GPs. Constantly moving goalposts, changing policies, and distasteful press coverage of GP salaries leave many doctors feeling jaded and unappreciated. Private foreign companies take over general practices and are paid handsomely for covering outof-hour healthcare needs of UK communities. Community hospitals, previously covered by local GPs, now struggle to find satisfactory medical cover.

GP working hours have never been better. The new contract released them from the enormous $24 / 7$ responsibility for their patients, but at what price? Little wonder the reputation of GPs - among hospital specialists and local communities - is not what it once was. Taking 24-hour responsibility out of the hands of local GPs has also seriously dented the public coffers. Doctors have been known to fly from European countries to do out-ofhours work in the UK: it is so well paid while UK GPs relax and enjoy their weekends.

As a profession, as a nation which for 60 years has benefited from the NHS and its GPs, as a government now financially pressed, finding itself on the brink of recession in the midst of a global economic disaster, we must act now. We cannot have doctors flying from Europe to care for our patients. We cannot have foreign private companies - who, after all is said and done, intend to make a profit take over UK general practices.

And as a profession we cannot cling to the past. It is time to move on. The selfemployed status of GPs will eventually have to go. And in its place, as in all other medical specialties, a clear career structure with the opportunity and incentive to progress amid the atmosphere of healthy professional competition. Small general practices have merged into larger organisations; the days of the single handed GP are passing. Darzi centres loom.

But nothing is yet big enough. Practices have to get bigger still, containing at least 30 whole-time equivalent GPs, salaried, and under the auspices of primary care trusts. Managerial and secretarial services need to merge and be centralised. And these large general practice organisations need to be given back what they once had. Out-of-hours will again be the remit of local GPs, not like in the past where doctors were permanently exhausted covering every other night, but in these large organisations each GP can be expected to be on-call one night monthly, and have the next day off - a longstanding anaesthetics practice. Community hospitals, their minor injury units, slow stream rehabilitation beds, and even some operation lists will again be run by local GPs.

These larger organisations will give more room for GPs to grow professionally. There will be more opportunities to develop special interests, and incorporate more variety into their working week. And, importantly, in an atmosphere of professional transparency, it will facilitate the regulation of GPs. Locally-run educational programmes will ensure every GP is up to date and fit to practice, and their practice be monitored more effectively.

Older people often struggle to attend surgery. Much GP time is spent travelling to home visits. To combat this regular community transport - a shuttle bus service between patients' homes and surgeries - should be in place, during the day and night.
General practice has changed. And it's going to change further. The financial landscape is no longer certain. But patients needs continue. We must ask ourselves how we will meet their needs and do it safely and financially efficiently. Merge. Become bigger and more efficient. This might have to be the future of general practice in the UK.

\section{Jeremy Gibson}

DOI: 10.3399/bjgp08X376339 